\title{
PARTICIPAÇÃO POLÍTICA: A CENTRALIDADE DOS REPERTÓRIOS
}

Julian Borba

\begin{abstract}
Resumo
O artigo analisa as relações entre as distintas modalidades de participação política, tomando como base empírica os casos de Brasil, Portugal e Chile. Os dados são oriundos do International Social Survey Programme. No referido estudo foram incluídas questões sobre 13 modalidades distintas de participação política. Os resultados confirmam as proposições teóricas que identificam as modalidades de participação como convergentes. Nesse sentido, o fato de um cidadão ser engajado em qualquer forma de participação (entre aquelas estudadas) é, em geral, um forte preditor de seu engajamento em qualquer outra modalidade. Apesar das diferenças internas entre os países em análise e do fato de que tais eviências tenham ficado mais claras para o Brasil e Portugal, a constatação acima tem validade para todo o universo da pesquisa.
\end{abstract}

Palavras-chave: Participação Política; Repertórios Políticos; Cultura Política.

\begin{abstract}
This article analyses the relations between different modalities of political participation, using as empirical framework the cases of Brazil, Portugal and Chile. The data were taken from the International Social Survey Programme. This study included questions regarding 13 distinct modalities of political participation. The results corroborate theoretical propositions which define these modalities as converging. In this sense, the fact that a citizen takes part in one form of participation (among those studied) is usually a strong predictor of their engagement in another modality. Despite internal differences between the countries under analysis and the fact that the evidence was clearer in regard to Brazil and Portugal, the above statement applies to the entire universe of the study.
\end{abstract}

Keywords: Political Participation; Political Repertoires; Political Culture.

\section{Introdução}

Parte considerável dos esforços analíticos dos estudiosos da participação política tem se direcionado para duas ordens de questões: quais os determinantes do engajamento individual nas distintas modalidades de participação e como se relacionam entre si tais modalidades. Elas se complementam ou são excludentes?

O ponto de partida de tal discussão é o fato de que desde a década de 1960 assiste-se a um alargamento do próprio conceito de participação (VAN DETH, 2001). Se até então, a participação política era tratada como um 
fenômeno exclusivamente ligado ao momento eleitoral das democracias (MILBRATH, 1965; VERBA e NIE, 1972), desde então, e em função da difusão da eclosão de novas formas de ação política, assiste-se a expansão do que Norris (2007, p. 639) denomina de modalidades de participação "causeoriented"1 , ou formas não convencionais de participação ${ }^{2}$. Della Porta (2003, p. 92), elenca algumas das formas pelas quais tais modalidades de participação podem se expressar ${ }^{3}$.
1) Escrever a um jornal;
2) Aderir a um boicote;
3) Auto-reduzir impostos ou rendas;
4) Ocupar edifícios;
5) Bloquear o trânsito;
6) Assinar uma petição;
7) Fazer um sit-in;
8) Participar numa greve;
9) Tomar parte em manifestações;
10) Danificar bens materiais;
11) Utilizar violência contra pessoas.

Esse alargamento do conceito de participação tem produzido um intenso debate metodológico sobre tipologias classificatórias (BORBA, 2011) e sobre como as distintas modalidades de participação se manifestam nos padrões comportamentais dos cidadãos. As posições no interior desse debate não têm sido consensuais na literatura internacional e parecem caminhar em duas direções.

Um conjunto de autores tem se posicionado pela divergência entre as modalidades de participação (INGLEHART e WELZEL, 2009; NORRIS, 2002; CLARK e HOFFMANN-MARTINOT, 1998). Podemos mencionar como ilustrativa dessa posição a "teoria do desenvolvimento humano" na forma como desenvolvida por Ronald Inglehart e colaboradores. O programa de pesquisa desenvolvido por Inglehart tem apontado para uma contínua alteração nos valores em nível mundial, resultante principalmente dos processos de modernização econômica vivenciados por alguns países a partir da segunda

\footnotetext{
${ }^{1}$ A pesquisa de Barnes e Kaase (1979) foi precursora no sentido de captar a emergência dessas novas modalidades de participação.

${ }^{2}$ Pesquisas empíricas têm apontado para o declínio ou estabilização das formas convencionais de participação (DALTON e WATTENBERG, 2001; PUTNAM, 2003) e para ampliação das não convencionais (DELLA PORTA, 2003; INGLEHART e CATTERBERG, 2002; NORRIS, 2007; WELZEL, INGLEHART e DEUTSCH, 2005; CATTERBERG, 2003).

3 Baquero e Prá (2007, p. 131) propõem a seguinte classificação quanto às modalidades de participação: 1) ações expressivas (ex. patriotismo e votar em eleições), 2) ações instrumentais (participar em campanhas), 3) comportamentos não convencionais (movimentos de protesto, passeatas). Já Lúcia Avelar (2004) diferencia entre, a) canal eleitoral (voto, partidos, etc...), b) canais corporativos (sindicatos, órgãos de classe), c) canal organizacional (movimentos sociais).
} 
metade do século XX. Estaríamos assistindo o desenvolvimento de uma cultura política pós materialista que teria entre suas características, a mudança

[...] da disciplina coletiva para a liberdade individual, da conformidade para a diversidade humana e da autoridade do estado para a autonomia individual - gerando uma síndrome que chamamos de valores de autoexpressão (INGLEHART e WELZEL, 2009, p. 19).

Uma das transformações originadas pela difusão dos valores de autoexpressão seria a emergência de atitudes mais críticas da cidadania para com as instituições políticas tradicionais (materializada entre outros fatores nos índices de desconfiança nas instituições), que teria como reflexo o declínio nas taxas de participação política nas modalidades ditas convencionais. Tal declínio, porém estaria sendo contrabalançado pelo crescimento do engajamento nas formas não convencionais de participação, ou naquilo que se denominou de elite-directed political action (NORRIS, 2002; INGLEHART e WELZEL, 2009). Dessa forma, os "cidadãos críticos" (NORRIS, 1999) ou "pós materialistas" concentrariam sua energias cívicas nessas modalidades, caracterizadas pela ação direta (sem a intermediação de representantes) e realizadas por organizações não hierárquicas. Exemplos seriam as manifestações coletivas, a organização de abaixo assinados, a participação numa ONG, etc. Da mesma maneira seria de esperar que cidadãos portadores de valores materialistas exerceriam sua participação política preferencialmente através das tradicionais instituições da democracia representativa: o voto, os partidos, os sindicatos.

Partindo de uma outra matriz teórica e epistemológica, a teoria da "nova" sociedade civil, na forma como formulada por autores como Cohen e Arato (1992) também chega a resultados semelhantes aos de Inglehart e colaboradores. O ponto de partida de tal teoria é a visão tripartite da estrutura social formulada por Jürgen Habermas. Os componentes de tal estrutura seriam o Estado, o mercado e o "mundo da vida". As duas primeiras esferas seriam guiadas pelas lógicas sistêmicas do dinheiro e do poder, enquanto a terceira deveria ser guiada pela lógica do "entendimento". Cada uma dessas estruturas desenvolve instituições próprias destinadas à sua reprodução. No caso do mundo da vida, Habermas percebe as organizações da sociedade civil como uma de suas expressões organizacionais, em especial os "novos movimentos sociais" (principalmente o feminista e o ambientalista). Tais instituições teriam como tarefa a defesa do mundo da vida contra os "ataques" colonizadores feitos pelas instituições do sistema no intuito de mercantilizar ou estatizar a estrutura social. Por outro lado, tais instituições também teriam uma função ofensiva no sentido de colocar novas questões ou 
problemas para a esfera pública, atuando de forma a gerar mudanças culturais.

Para além dos aspectos internos à teoria da ação comunicativa, nos interessa destacar que a teoria da sociedade civil de Cohen e Arato (2002) ao enquadrar os atores da sociedade civil na esfera do mundo da vida, vai resultar numa teoria da participação política que delimita a ação dos atores sociais ao espaço por eles ocupado na estrutura social. Nesse sentido, não haveria interface entre a participação exercida pelos movimentos sociais (típicas formas não convencionais na definição acima), os partidos políticos e os sindicatos, por exemplo, pois cada um deles seria regido por lógicas e bases sociais distintas. Enquanto os dois últimos estariam inseridos na lógica sistêmica do Estado e do mercado, respectivamente, os primeiros seriam guiados pela lógica do entendimento.

Em que pese o caráter normativo de tal construção teórica, tal interpretação teve um impacto bastante significativo no debate sobre participação política, em especial no entendimento que se produziu sobre os "novos movimentos sociais" e ONGs. Tais atores teriam uma lógica de ação auto-limitada, não desenvolvendo interfaces com as modalidades de participação orientadas pela lógica do poder administrativo (a ação dos partidos políticos) ou por demandas de classe ou corporações (a ação dos sindicatos, por exemplo). Nesse sentido, aqui também as modalidades de participação seriam "divergentes", pois de acordo com os pressupostos (normativos) de tal teoria seria de se esperar que não houvessem relações entre os atores participantes de cada uma dessas modalidades ${ }^{4}$.

Como contraponto a essas visões divergentes, temos as teorias que defendem a convergência entre as distintas modalidades de participação. 0 núcleo articulador de tais formulações é o conceito de "repertórios políticos", cuja origem pode ser encontrada na obra Political Action (BARNES e KAASE, 1979). Na referida pesquisa, ao estudar distintas modalidades de participação em cinco países, os autores identificam que aqueles cidadãos que se engajam em modalidades não convencionais não seriam opositores ortodoxos da participação política convencional ${ }^{5}$. Dizem eles que "active partisans will signal their discontent and demands for redress of political grievances through a mixture of political methods" (BARNES e KAASE, 1979, p. 150). Através de testes de associação entre modalidades de participação concluem que "in each country conventional and unconventional political participation are positively correlated" (BARNES e KAASE, 1979, p. 152).

Considerando tal articulação entre formas convencionais e não convencionais de participação, os autores constroem uma escala do ativismo

\footnotetext{
${ }^{4}$ Para uma interpretação da ação política da sociedade civil na referida perspectiva, ver Costa (2002) e Avritzer (1996). Para uma análise crítica de tal abordagem ver Lavalle (2003).

${ }^{5}$ Deve-se destacar que a tese da convergência já havia sido formulada por Almond e Verba em seu clássico The civic culture (1963). Para outros estudos empíricos sobre o tema, vide Erickson e Nosanchuk (1990) e Leighley (1996).
} 
político, que vai dos inativos aos "protesters". O que determinaria o nível de ativismo seria a "competência política subjetiva". Já a mobilização de diferentes repertórios seria produto do contexto.

Stolle e Hooghe (2004) ao estudar as novas modalidades de ação política, carcterizadas pela horizontalidade, fluidez e seu caráter direto, questionam se os ativistas de tais modalidades teriam excluído as modalidades tradicionais (convencionais) de seus repertórios. Sua conclusão endossa o caráter convergente das diversas modalidades de participação:

\begin{abstract}
Clearly, [...] those active in new forms are also those who engage in traditional style politics. New action repertoires are being added to existing action repertoires. This relationship is even more extreme in the case of those who engage in protest politics. In other words, it seems as if those who engage in new forms of participation are not necessarily those who oppose the current political structures, or at least they have not completely dropped out of the traditional political process. In fact, only $1 \%$ of the entire ESS sample respondents have only engaged in new forms of participation while at the same time avoiding all forms of conventional engagement including voting. And only $3.5 \%$ of the sample has engaged in new forms but nothing traditional except voting. This evidence does not fare well with the claims of the postmodern camp (STOLLE e HOOGHE, 2004, p. 10).
\end{abstract}

Considerando tal articulação entre as modalidades de participação, juntamente com a idéa de competência política subjetiva, Donatella Della Porta (2003) ao fazer um balanço dos estudos sobre participação, afirma que:

[...] com efeito, a participação convencional está com frequência relacionada com a não convencional, indicando que pessoas interessadas na política e competentes no campo tendem a utilizar simultaneamente vários instrumentos possíveis para pressionar os governos. Se há indivíduos que preferem um ou outro tipo de estratégia, existem muitos que os combinam entre si (DELLA PORTA, 2003, p. 93).

[...] a investigação mais recente confirma que as formas de participação não convencionais são complementares, e não alternativas, em relação às convencionais (DELLA PORTA, 2003 , p. 96, grifos nossos).

Resta verificar, porém, como se relacionam repertórios e contextos. Estudos como o de Stolle e Hooghe (2004), Norris (2007), Dalton (2002) têm verificado que a mobilização de diferentes formas de participação e sua articulação é afetada por aspectos do contexto (institucional, histórico, econômico, etc., de modo que, por exemplo, países com maior tradição 
democrática, são aqueles onde encontram-se maiores níveis de exercício das novas modalidades de participação (STOLLE e HOOGHE, 2004). Para entender essa relação entre repertórios e contexto, vale inserir a reflexão de Tilly (2006, p. 35):

Repertory vary from place to place, time do time, and pair to pair. But on the whole, when people make collective claim they innovate within limits set by the repertoire already established for their place, time and pair. Thus socialmovement activists in today's European cities adopt some mixture of public meetings, press statements, demonstrations, and petitions, but stay away from suicidebombing, hostage-taking, and self-immolation. Their repertorie draws on a long history of previous struggles.

Tomando as interpretações acima sobre as relações entre as modalidades de participação, e o fato de que os testes empíricos que sustentam tais diagnósticos têm sido realizados sobretudo no âmbito de democracias já institucionalizadas, o presente trabalho se propõe a buscar evidências empíricas sobre o referido fenômeno tomando como base os casos de Brasil, Portugal e Chile, países que fazem parte da chamada "terceira onda" de democratização (HUNTINGTON, 1994). Nesse sentido, a justificativa para tal escolha está relacionada a essa dimensão do contexto, de todos serem jovens democracias, apesar das diferenças de modo de transição e do próprio período em que ocorre a mudança de regime.

Os dados são oriundos de um survey aplicado dentro do programa ISSP $(2004)^{6}$. No referido estudo foram incluídas questões sobre 13 modalidades distintas de participação política?. No Brasil a pesquisa foi

\footnotetext{
6 "O International Social Survey Programme (ISSP) é a mais antiga e vasta rede internacional de estudos comparativos e longitudinais, envolvendo a aplicação anual de questionários comuns em mais de quatro dezenas de países. [...] Os inquéritos ISSP são aplicados anualmente a amostras representativas das populações dos países participantes, com 18 ou mais anos, sem limite superior, independentemente da sua nacionalidade ou situação legal.

o questionário é constituído por dois módulos: um módulo temático e um módulo sociodemográfico, que abrange domínios como caracterização demográfica, educação, ocupação, rendimentos, classe social, participação política e religiosa." Disponível em: <http://www.atitudessociais.org/issp/index.html>. Acesso em: $01 \mathrm{dez}$. 2010. No ano de 2004, 0 módulo temático foi cidadania, onde constava de um conjunto de questões destinadas a mensurar o conceito de cidadania, entre elas, aquelas relacionadas às modalidades de participação.

7 As perguntas eram elaboradas da seguinte forma: (a) "Estas são algumas formas de acção política e social a que as pessoas podem recorrer. Para cada uma, indique se fez alguma delas no último ano, em anos anteriores, se seria capaz de o fazer ou se nunca o faria". (v125) Assinar uma petição ou fazer um abaixo-assinado (v126) comprar ou não comprar de propósito determinados produtos, por razões políticas, éticas ou ambientais, (v127) Participar numa manifestação, (v128) Participar num comício ou numa reunião política, (v129) Contactar, ou tentar contactar, um político ou um alto funcionário do Estado, (v130) Dar dinheiro ou participar em peditórios para uma causa pública, (v131) Contactar ou aparecer na Comunicação Social para
} 
realizada em janeiro de 2006, com uma amostra de 2000 respondentes. No Chile, entre junho e julho de 2005, com 1505 respondentes. Em Portugal, entre abril e agosto de 2004 com uma amostra de 1602 casos.

\section{Descrição e análise dos dados}

Iniciamos nossa análise com uma descrição das frequências de engajamento de portugueses, brasileiros e chilenos em cada uma das modalidades de nosso estudo (Tabela 1). Para fins de análise, excluímos da tabela os percentuais de não participação. Considerando os abaixo assinados, - Brasil apresenta os maiores percentuais com $24,2 \%$ dos respondentes afirmando que participaram em anos anteriores e $9,4 \%$ no último ano. Logo em seguida aparece Portugal (com $24,6 \%$ e $6,4 \%$, respectivamente). No Chile os percentuais são de $9,9 \%$ e $5,3 \%$. Nas atividades de boicote, Portugal fica acima dos demais países, o mesmo acontecendo com manifestações e contato político. Já o Chile aparece a frente nas atividades de doação de dinheiro (17\% doou dinheiro no último ano e $14,1 \%$ em anos anteriores), seguido pelo Brasil (7,9\% e 2,3\%, respectivamente). Portugal volta a apresentar os maiores percentuais nas atividades de comparecer a comunicação social e na participação em fóruns na internet. A participação em partidos é bastante semelhante nos três países, estando o Brasil ligeiramente a frente $(3,7 \%$ pertencem mas não participam e $2,8 \%$ participam ativamente), seguido por Portugal $(3,7 \%$ e $2,0 \%)$. O Chile tem $2,6 \%$ e $0,9 \%$ respectivamente. No caso de sindicatos, os valores também são bastante semelhantes para Portugal e Brasil, estando o primeiro ligeiramente a frente $(8,2 \%$ pertencem mas não participam e $4,1 \%$ participam ativamente). Nas organizações religiosas, $20,9 \%$ dos brasileiros participam ativamente, mesmo valor dos que pertencem mas não participam, seguido pelo Chile onde $20,5 \%$ participam ativamente e $16,5 \%$ pertencem mas não participam. Em Portugal $14,8 \%$ é o percentual dos que participam ativamente ou pertencem mas não participam. No caso de grupos esportivos, o Chile aparece a frente com $14,1 \%$ dos que participam ativamente. Portugal e Brasil apresentam valores semelhantes para essa modalidade. No que se refere as outras organizações voluntárias $7,3 \%$ dos chilenos participam ativamente, contra 3,3\% que pertencem mas

exprimir as suas opiniões, ( 132 ) Participar num fórum ou grupo de discussão através da Internet. A segunda pergunta era: (b) "Por vezes as pessoas participam em grupos ou associações. Para cada um dos grupos que lhe vou mencionar, diga, se participa activamente, se pertence mas não participa activamente, se já pertenceu ou se nunca pertenceu". (v133) Partido político, (v134) Sindicato, grémio ou associação profissional, (v135) Igreja ou outra organização religiosa, (v136) Grupo desportivo, cultural ou recreativo, (v137) Outra associação voluntária. A codificação original da pergunta (a) era (1) fez alguma delas no último ano, (2) em anos anteriores, (3) seria capaz de o fazer, (4) nunca o faria. Na pergunta (b): (1) participa activamente, (2) pertence mas não participa activamente, (3) já pertenceu, (4) nunca pertenceu. As duas perguntas tiveram sua codificação invertida, indo de 0 (nunca o faria, nunca pertenceu) a 3 (participa ativamente, fez alguma delas no último ano). 
não participam. Entre os brasileiros 3,4\% participam ativamente contra 4,0\% que pertencem mas não participam. Já entre os portugueses $5,2 \%$ participam ativamente e $4,2 \%$ pertencem mas não participam.

Tabela 1 - Participação Política: Portugal, Brasil e Chile \%

\begin{tabular}{l|c|c|c|c|c|c|c|c|c}
\hline & \multicolumn{3}{|c|}{ Portugal } & \multicolumn{3}{c|}{ Brasil } & \multicolumn{3}{c}{ Chile } \\
\cline { 2 - 10 } & 1 & 2 & 3 & 1 & 2 & 3 & 1 & 2 & 3 \\
\hline Abaixo Assinados & 53,5 & 24,6 & 6,4 & 37,9 & 24,2 & 9,4 & 20,9 & 9,9 & 5,3 \\
\hline Boicote & 56,5 & 13,6 & 7,0 & 28,3 & 6,4 & 3,2 & 8,7 & 1,9 & 3,2 \\
\hline Manifestação & 45,5 & 23,7 & 2,7 & 34,7 & 15,1 & 3,6 & 9,8 & 11,0 & 2,9 \\
\hline Comício & 45,5 & 19,5 & 2,3 & 23,6 & 30,8 & 7,3 & 8,7 & 2,1 & 2,5 \\
\hline Contato & 62,0 & 7,4 & 2,0 & 34,0 & 7,4 & 3,7 & 21,9 & 6,5 & 6,1 \\
\hline Dar Dinheiro & 29,6 & 36,4 & 23,2 & 38,7 & 7,9 & 2,3 & 15,8 & 14,1 & 17,0 \\
\hline Contatar ou & 58,7 & 5,0 & 1,3 & 35,5 & 2,6 & 1,3 & 20,6 & 3,0 & 2,1 \\
$\begin{array}{l}\text { Comparecer na } \\
\text { Comunicação Social }\end{array}$ & 44,0 & 3,2 & 3,5 & 29,8 & 2,7 & 2,9 & 13,2 & 0,7 & 1,4 \\
\hline Fórum na Internet & 4,7 & 3,7 & 2,0 & 7,4 & 3,7 & 2,8 & 4,9 & 2,6 & 0,9 \\
\hline Partido & 15,1 & 8,2 & 4,1 & 14,4 & 8,0 & 5,1 & 7,2 & 2,7 & 4,1 \\
\hline Sindicato & 8,0 & 14,8 & 14,8 & 13,9 & 20,9 & 20,9 & 10,5 & 16,5 & 20,5 \\
\hline Igreja & 16,1 & 6,9 & 6,6 & 13,8 & 7,3 & 4,8 & 12,9 & 6,8 & 14,1 \\
\hline Grupo esportivo & 8,4 & 4,2 & 5,2 & 8,7 & 4,0 & 3,4 & 7,3 & 3,3 & 7,3 \\
\hline $\begin{array}{l}\text { Outras Associações } \\
\text { Voluntárias }\end{array}$ & & & & & & & & \\
\hline
\end{tabular}

Fonte: ISSP (2004).

Para verificar as relações entre as distintas modalidades de participação nos três países, procedemos à realização de distintos testes estatísticos. Em primeiro lugar, buscamos fazer uma redução dos dados, buscando verificar em quantas dimensões as distintas modalidades de participação verificadas no estudo estariam agrupadas. Para isso, utilizamos a técnica da análise fatorial por componentes principais ${ }^{8}$.

Os resultados estão apresentados na Tabela 2, abaixo.

\footnotetext{
${ }^{8} \mathrm{~A}$ análise fatorial é um termo genérico utilizado para se referir a um conjunto de métodos estatísticos multivariados que visam principalmente a redução e sumarização de dados, ou seja, trata-se de um procedimento de redução de dimensionalidade. Ela analisa as relações entre variáveis e tenta explicá-las em termos de suas dimensões subjacentes comuns (fatores). Para fins de análise dos dados, foram considerados relevantes os fatores que carregam acima de 0,45. Para detalhes sobre essa técnica de análise consultar Hair et. al. (1984).
} 
Tabela 2 - Análise Fatorial das modalidades de Participação: Portugal, Brasil e Chile

\begin{tabular}{l|c|c|c|c|c|c|c|c}
\hline & \multicolumn{3}{|c}{ Portugal } & \multicolumn{3}{c|}{ Brasil } & \multicolumn{2}{c}{ Chile } \\
\cline { 2 - 9 } & 1 & 2 & 3 & 1 & 2 & 3 & 1 & 2 \\
\hline Abaixo Assinados &, 660 & & &, 555 & & &, 634 & \\
\hline Boicote &, 616 & & &, 605 & & &, 579 & \\
\hline Manifestacao &, 776 & & &, 695 & & &, 755 & \\
\hline Comicio &, 766 & & &, 470 & &, 546 &, 732 & \\
\hline Contato &, 686 & & &, 585 & &, 425 &, 679 & \\
\hline Dar Dinheiro & & &, 601 &, 521 & & &, 574 & \\
\hline $\begin{array}{l}\text { Contactar ou Comparecer } \\
\text { na Comunicacao Social }\end{array}$ &, 673 & & &, 616 & & &, 739 & \\
\hline Forum na Internet &, 687 & & &, 656 & & &, 717 & \\
\hline Partido & & &,- 572 & & &, 657 & & \\
\hline Sindicato & &, 554 & & &, 429 & & & \\
\hline Igreja & &, 592 & & & &, 560 & &, 614 \\
\hline Grupo Esportivo & &, 640 & & &, 723 & & &, 553 \\
\hline $\begin{array}{l}\text { Outras Associaçoes } \\
\text { Voluntarias }\end{array}$ &, 698 & & &, 714 & & &, 545 \\
\hline
\end{tabular}

Extraction Method: Principal Component Analysis. Rotation Method: Varimax with Kaiser Normalization

Variância explicada fator 1: Portugal 29\%, Brasil 23\%, Chile 29,4

Variância explicada fator 2:Portugal 14,8\%, Brasil 12,5, Chile 14,0

Variância explicada fator 3: Portugal 8,5\%, Brasil 11,7

Alpha de Cornbah componentes do fator 1: Portugal ,815, Brasil ,781, Chile ,823

Alpha de Cornbah componentes do fator 2: Portugal ,784, Brasil ,524, Chile ,413

Fonte: Elaboração própria.

Todos os países incluídos na amostra produziram agrupamentos semelhantes, com a diferença que Portugal e Brasil produziram agrupamentos com três fatores e o Chile com dois. Outra diferença foi que em Portugal doar dinheiro agrupou negativamente com participação em partidos (fator 3 ). No caso do Brasil, participação em igrejas agrupou com participação em partidos, realização de contato político e participação em comícios.

A resultante indica que as 13 modalidades de participação podem ser reduzidas a dois grandes fatores, os quais se relacionam às duas modalidades de participação conceituadas por Cabral (2009) como mobilização (componentes do fator 1 nos três países) e participação associativa (componentes do fator 2 nos três países). A primeira delas segundo Cabral é "uma modalidade [...] de envolvimento cívico e político individual ou grupal em manifestações, petições, debates na internet" (CABRAL, 2009, p. 334) ${ }^{9}$. Já

\footnotetext{
${ }^{9}$ A distinção entre as duas modalidades tem como fundamento "a diferença entre, por um lado, formas relativamente passivas de envolvimento como membro de uma associação, especialmente grandes instituições históricas como os partidos políticos e os sindicatos, que se ocupam de aspectos gerais da vida social e economica; e por outro lado, formas pró-ativas de mobilização, de tipo pontual e geralmente orientadas para questões específicas (issue-oriented)" (CABRAL, 2009 , p. 334).
} 
a participação associativa seria caracterizada pela participação do indivíduo como membro de organizações sociais e políticas, que na perspectiva de Cabral pode ser considerada uma proxy de capital social, na forma como definido por Putnam (1996). Tal distinção se aproxima daquela entre participação convencional (segunda) e não convencional (primeira) descrita acima.

Para além dessas duas modalidades de participação, procedemos a análise em separado da participação em partidos das demais formas de participação associativa. A justificativa é pelo fato de que nos três países essa modalidade apresentou cargas fatoriais distintas, ora agrupando negativamente com doação de dinheiro (Portugal), não agrupando com nenhuma modalidade (Chile), ou agrupando com igrejas, comícios e contato político (Brasil).

Feita essa redução dos dados, realizamos três conjuntos de testes para responder ao problema de pesquisa colocado acima. O primeiro foi um teste de associação Gamma ${ }^{10}$ entre as modalidades de participação (agrupadas e de forma individualizada). O pressuposto é de que, se as modalidades são divergentes elas não se associariam entre si, sendo o inverso para existência de associação ${ }^{11}$. Os resultados estão apresentados na Tabela 3, abaixo e nas Tabelas anexas 1, 2 e 3 :

Tabela 3 - Associação Gamma entre Modalidades de Participação

\begin{tabular}{l|c|c|c}
\hline & Portugal & Brasil & Chile \\
\hline Mobilização x Participação Associativa &, $301 * * *$ &, $445 * * *$ &, $264 * * *$ \\
\hline Mobilização x Participação em Partidos &, $541^{* * *}$ &, $433 * * *$ &, $569 * * *$ \\
\hline $\begin{array}{l}\text { Participação Associativa x Participação em } \\
\text { Partidos }\end{array}$ &, $532 * * *$ &, $467 * * *$ &, $403 * * *$ \\
\hline
\end{tabular}

Fonte: Elaboração própria.

Como pode ser visto na tabela acima, para todos os três países as distintas modalidades de participação estão associadas entre si, sendo que o menor nível de associação foi verificado no Chile entre participação associativa e mobilização, e o maior, também no Chile entre mobilização e participação em partidos. Todas as associações são significativas a 0,00. Analisando as distintas modalidades de participação de forma desagregada (Tabelas 1, 2 e 3, em anexo), os resultados também são inequívocos para todos os três países, sendo que a única variável que não apresentou alguma

\footnotetext{
10 O teste Gamma de Goodman e Kruskal é útil nos casos em que as variáveis são qualitativas e medidas no nível ordinal, ou seja, com valores agrupados em categorias ordenadas (os valores vão de $-1 \mathrm{a}+1$, sendo que quanto mais se afastam do zero maior é a intensidade da associação) (BOHRNSTEDT, KNOKE e MEE, 1982).

${ }^{11} \mathrm{O}$ teste de associação entre as modalidades de participação tem sido usado nos principais estudos da área. Vide Barnes e Kaase (1979), Verba, Schlozman e Brady (1995), Teorel, Torcall e Montero (2007).
} 
associação com outras modalidades de participação foi "participação em igrejas ou organizações religiosas". As demais modalidades, todas estiveram associadas numa significância de 0,000.

O segundo teste que realizamos é desdobrado em dois procedimentos analíticos. Ambos estão relacionados à análise de regressão linear múltipla ${ }^{12}$. No primeiro deles, comparamos os Adjusted $R$ Square ${ }^{13}$ em três modelos (para cada uma das modalidades de participação como dependentes): um, apenas com variáveis sócio-demográficas como independentes ${ }^{14}$, 0 segundo incluindo variáveis atitudinais ${ }^{15}$ e o terceiro, incluindo as próprias variáveis de participação ${ }^{16}$. A expectativa era de que se as modalidades de participação fossem divergentes elas não exerceriam qualquer efeito sobre a adequação do modelo de regressão após sua inclusão. Caso contrário, seria um indicativo de que elas são "convergentes".

\footnotetext{
${ }^{12}$ Os modelos de regressão linear múltipla relacionam uma variável $\mathrm{Y}$, denominada variável dependente com um conjunto de medidas chamadas independentes ou preditoras ( $\mathrm{Xi}, \mathrm{Xii} . .$.$) . \mathrm{O}$ pressuposto do modelo é a existência de relação linear entre as variáveis dependente e independentes. $\mathrm{O}$ modelo permite verificar a influência de cada uma das variáveis $\mathrm{X}$ sobre $\mathrm{Y}$.

${ }^{13} \mathrm{O}$ Adjusted $R$ Square é um indicador de ajuste do modelo de regressão. Os valores vão de 0 a 1 , e quanto mais próximo de 1 maior a capacidade explicativa das variáveis componentes do modelo.

14 São elas: escolaridade, idade, sexo, estado civil, classe social subjetiva, empregado, desempregado, estudante, tamanho do município.

15 São elas: simpatia partidária, identificação ideológica, católico, nível de informação geral, adesão a democracia, percepção da corrupção, avaliação da democracia, avaliação positiva dos partidos políticos, confiança interpessoal e interesse por política.

${ }_{16}$ Aqui incluimos as modalidades de participação como variáveis independentes. Nesse caso, quando a variável dependente era ação política, foram incluídas como dependente: votou (para Chile e Portugal - No caso do Brasil não havia a pergunta no survey), participação associativa e participação em partidos. Nas demais variáveis foi adotado o mesmo procedimento, apenas com a troca das variáveis dependentes e independentes.
} 
Tabela 4 - Comparação dos Adjusted R Square

\begin{tabular}{|c|c|c|c|}
\hline \multicolumn{4}{|c|}{ Variável dependente: Mobilização } \\
\hline & Portugal & Brasil & Chile \\
\hline Modelo com variáveis socio-demográficas & 336 & 113 & ,081 \\
\hline $\begin{array}{l}\text { Modelos com variáveis sócio-demográficas e } \\
\text { atitudinais }\end{array}$ & ,373 & ,221 & , 184 \\
\hline Modelo com variáveis de comportamento político & 413 & 341 & 252 \\
\hline \multicolumn{4}{|c|}{ Variável dependente: Associações Políticas } \\
\hline Modelo com variáveis socio-demográficas & ,077 & 106 & 022 \\
\hline $\begin{array}{l}\text { Modelos com variáveis sócio-demográficas e } \\
\text { atitudinais }\end{array}$ & 123 & 159 & ,046 \\
\hline Modelo com variáveis de comportamento político & 190 & 292 & 099 \\
\hline \multicolumn{4}{|c|}{ Variável dependente: Partidos Políticos } \\
\hline Modelo com variáveis socio-demográficas & ,066 & 015 & 020 \\
\hline $\begin{array}{l}\text { Modelos com variáveis sócio-demográficas e } \\
\text { atitudinais }\end{array}$ & 127 & 128 & ,088 \\
\hline Modelo com variáveis de comportamento político & 196 & 193 & 124 \\
\hline
\end{tabular}

Os resultados (Tabela 4) indicam que em todas as modalidades de participação e em todos os países, aumenta-se em muito a adequação dos modelos com a inclusão das variáveis de participação como independentes uma das outras. Em alguns casos, aumenta em mais de $20 \%$ a capacidade explicativa do modelo com tal inclusão (em relação ao modelo simples). É o caso da mobilização no Brasil e no Chile. Mesmo que em alguns casos os efeitos tenham sido menores (participação associativa no Chile e mobilização política em Portugal), eles são bastante significativos.

A Tabela seguinte (5) apresenta o modelo de regressão completo, com os coeficientes para cada uma das variáveis independentes. Aqui também a expectativa era de que se as modalidades de participação não estivessem associadas, não haveria efeito em termos de coeficiente de regressão, sendo a conclusão inversa para a existência de efeito.

Começando a análise pelas modalidades de mobilização política verifica-se que em todos os países as modalidades de participação política, com exceção do voto, apresentaram efeitos significativos na explicação da variável dependente. No caso do Brasil, participação associativa se mostrou inclusive o principal preditor (Beta 0,323). No Chile foi o segundo (Beta 0,191 ). Em Portugal, apesar do efeito ter sido menor, quando comparado com as demais variáveis, mesmo assim, participação em partidos e em associações políticas alcançaram Betas significativos $(0,144$ e 0,139, respectivamente), sendo significantes a 0,000 . Os casos de Chile e Portugal também confirmam o que outros estudos já haviam identificado (TEOREL, TORCALL e MONTERO, 2007; VERBA, SCHLOZMAN e BRADY, 1995; BRADY, 
1999; DALTON, 2002), de que o voto é uma modalidade de participação com bases distintas das demais ${ }^{17}$.

No que se refere às modalidades de participação associativa os resultados são ainda mais significativos. Nesse caso, a mobilização se constitui no principal preditor de participação associativa para os três países em análise (Beta de 0,192 em Portugal, 0,347 no Brasil e 0,230 no Chile). Já participação em partidos apresentou efeitos significantes nos casos de Brasil e Portugal (terceiro e segundo maiores efeitos, respectivamente). No caso do voto, ele apresentou Beta significativo para o caso de Portugal, mesmo assim com efeito bastante baixo. Para os demais países não alcançou significância estatística mínima.

Por fim, tomando a participação em partidos como variável dependente, novamente as variáveis de participação foram as que exerceram os maiores efeitos. Nesse caso, a mobilização teve novamente os maiores Betas para todos os países e participação associativa o segundo maior em Portugal e terceiro no Brasil. No Chile, participar em associações políticas não exerceu efeito sobre participação partidária.

${ }^{17}$ No survey aplicado no Brasil não havia a pergunta sobre comparecimento eleitoral. 
A SITUAÇÃO DAS AMÉRICAS:

DEMOCRACIA, CAPITAL SOCIAL E EMPODERAMENTO

Tabela 5 - Determinantes de ação política

\begin{tabular}{|c|c|c|c|c|c|c|c|c|c|}
\hline & \multicolumn{3}{|c|}{ Mobilização política } & \multicolumn{3}{|c|}{ Associação Política } & \multicolumn{3}{|c|}{ Partidos Políticos } \\
\hline & Portugal & Brasil & Chile & Potugal & Brasil & Chile & Portugal & Brasil & Chile \\
\hline Escolaridade & $218 * * *$ & $109 * * *$ & $*, 112 * *$ & 072 & $166 * * *$ &, 011 &,- 077 &,$- 095 *$ &,- 018 \\
\hline Idade &,$- 099 *$ &,- 029 &,$- 078 *$ & $167 * * *$ & ,040 & 046 & 014 & ,097* & ,099* \\
\hline Sexo (mulher) &,- 011 &, 035 &,- 029 &,$- 101 * *$ &,$- 073 * *$ &,- 055 &,- 044 &,- 005 &,- 034 \\
\hline $\begin{array}{l}\text { Estado civil } \\
\text { (Casado) }\end{array}$ &,- 014 & NI & NI & ,053 & & NI &,- 019 & NI & NI \\
\hline $\begin{array}{l}\text { Classe Social } \\
\text { Subjetiva }\end{array}$ & ,006 & ,013 & ,002 & ,029 &,- 042 & $077 *$ &, $141 * * *$ &, 022 &, 004 \\
\hline Empregado & ,072 & ,070* &, 024 & $115^{*}$ &,- 001 &,- 077 &,- 073 & ,044 &,- 027 \\
\hline Desempregado & , , 004 & ,074* &,- 003 &, 001 &,$- 069 *$ &,- 048 &, 005 & ,075* &, 009 \\
\hline Estudante & ,084* & ,059* &,- 001 &, 048 &,- 031 &,- 034 &,- 063 &, 034 &, 036 \\
\hline $\begin{array}{l}\text { Tamanho do } \\
\text { Municipio }\end{array}$ &, $121 * * *$ &,- 007 & NI &,- 047 &,- 003 & NI &,- 013 &,- 049 & NI \\
\hline $\begin{array}{l}\text { Simpatia } \\
\text { Partidária }\end{array}$ & , 366*** &,- 183 & NI & ,086 & ,080 & NI &,- 103 & 181 & NI \\
\hline $\begin{array}{l}\text { Identificação } \\
\text { Ideológica }\end{array}$ & ,434*** &,- 188 & NI & , 102 & ,011 & NI &,- 146 & ,065 & NI \\
\hline Católico & $100 * * *$ &,- 022 &,- 033 &,- 027 &,- 005 &,$- 077 *$ &,- 010 &,- 016 & 013 \\
\hline $\begin{array}{l}\text { Nível de } \\
\text { informação }\end{array}$ & $120 * * *$ & ,048 & NI & ,073* & ,070* & NI & ,020 &, 054 & NI \\
\hline $\begin{array}{l}\text { Adesão a } \\
\text { Democracia }\end{array}$ &,- 027 &,- 019 &, $060 *$ &, $117 * * *$ &, 042 &,$- 064^{*}$ &,- 018 &,- 009 &,- 016 \\
\hline $\begin{array}{l}\text { Percepção } \\
\text { Corrupção }\end{array}$ & ,032 & ,062* &,- 031 & ,032 &,- 021 & ,008 & ,035 &,- 035 &,- 026 \\
\hline $\begin{array}{l}\text { Avaliação da } \\
\text { Democracia }\end{array}$ & NI & ,022 & ,038 & NI & ,019 & ,003 & ,004 &,- 036 & ,043 \\
\hline $\begin{array}{l}\text { Perc. Positiva } \\
\text { dos Partidos }\end{array}$ & ,040 &,- 046 &,- 052 & ,010 &,- 002 &,- 020 & ,016 & ,039 & ,001 \\
\hline $\begin{array}{l}\text { Confiança } \\
\text { Interpessoal }\end{array}$ &,- 007 &,- 003 & 009 &,- 048 & ,034 &, 060 &, 045 &,- 040 & ,040 \\
\hline $\begin{array}{l}\text { Interesse por } \\
\text { Política }\end{array}$ &, $129 * * *$ & ,207*** & $*, 240 * * *$ & * , 016 & ,039 & ,054 &, $171 * * *$ & $193 * * *$ & $172 * * *$ \\
\hline Votou &,- 019 & NI & ,018 & ,076* & NI &,- 015 &, 054 & $\mathrm{NI}$ &, 000 \\
\hline $\begin{array}{l}\text { Associações } \\
\text { Políticas }\end{array}$ &, $139 * * *$ &, $323 * * *$ & $*, 191 * * *$ & - & - & - &, $172 * * *$ &, $123 * * *$ & , 060 \\
\hline Mobilização & - & - & - & $192 * * *$ & , $347 * * *$ &, $230 * * *$ & , $198 * * *$ &, $189 * * *$ &, $211 * * *$ \\
\hline $\begin{array}{l}\text { Particip. Em } \\
\text { Partidos }\end{array}$ & $144 * * *$ & $154 * * *$ & $*, 180 * * *$ & $*, 172 * * *$ &, $108 * * *$ & ,061 & - & - & - \\
\hline $\begin{array}{l}\text { Adjusted } R \\
\text { Square }\end{array}$ & ,413 & ,341 & 252 & 190 & 292 & ,099 & 196 & 193 & 124 \\
\hline
\end{tabular}

Considerando os dados no seu conjunto fica evidente o efeito mútuo exercido pelas diferentes modalidades de participação, ganhando corpo o 
argumento de que existe uma convergência nos atos participativos, de modo que o ativista o é, em diferentes modalidades, e faz uso delas, de acordo com as oportunidades e constrangimentos oferecidos pelo contexto.

Como último teste confirmatório do argumento da convergência, fizemos um teste de homogeneidade (HOMALS) ${ }^{18}$ entre as modalidades de participação, onde é possível verificar, no âmbito interno à escala de participação entre as distinas modalidades, se elas estão agrupadas e de que modo se agrupam. Os resultados estão apresentados nos três gráficos abaixo.

Gráfico 1 - HOMALS. Modalidades de Participação Brasil

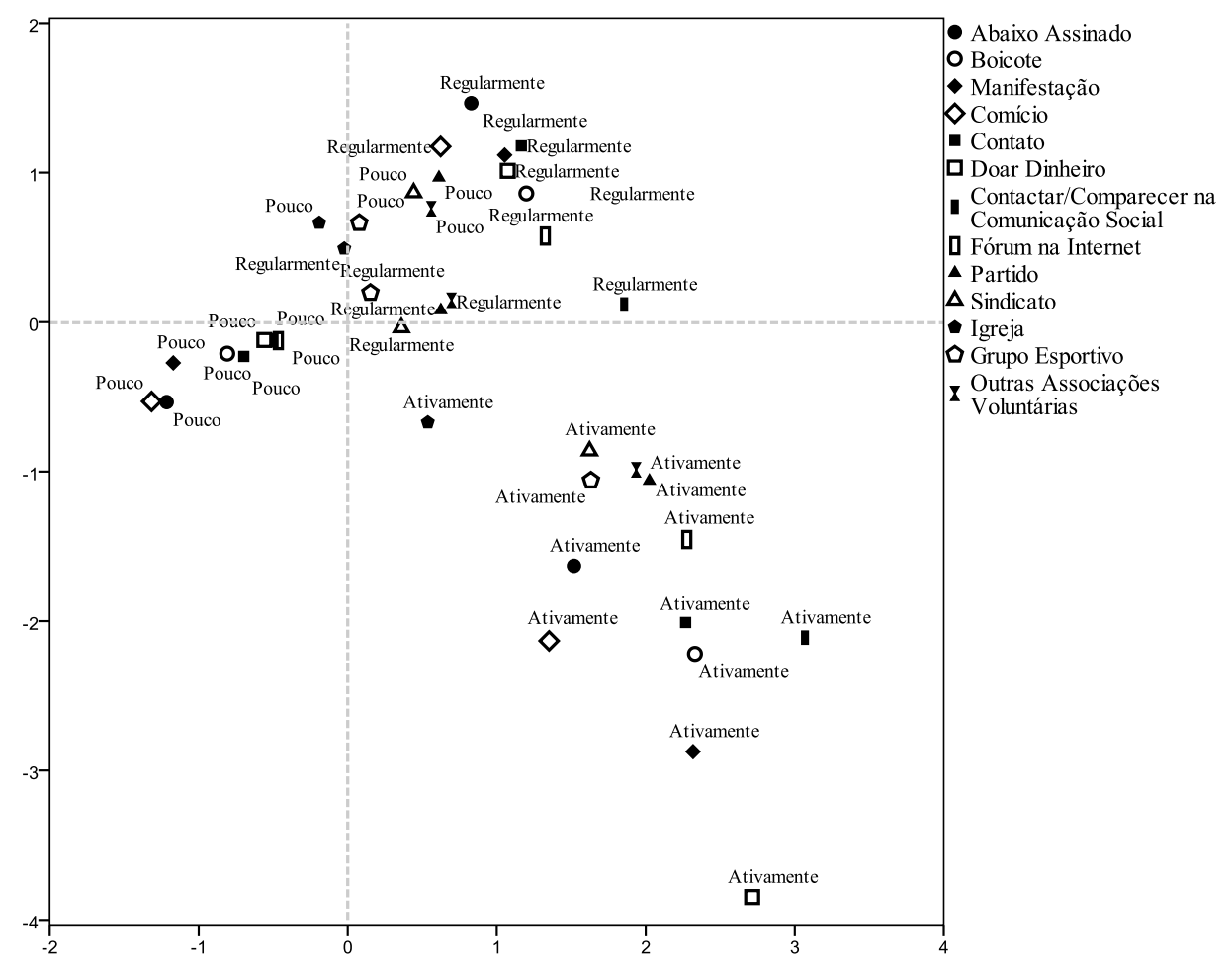

Fonte: Elaboração própria.

${ }^{18}$ O teste Homals "É [...] uma estatística de redução dos dados, pela análise de correspondência múltipla, com uma série de variáveis, todas nominais múltiplas. Isto é, o procedimento HOMALS analisa a relação de homogeneidade entre as variáveis [das colunas (columns) e das linhas (rows)] em duas dimensões, produzindo gráficos correspondentes, sendo o mais importante o gráfico das quantificações das categorias (category quantification)" (FIGUEIRA, 2011). 


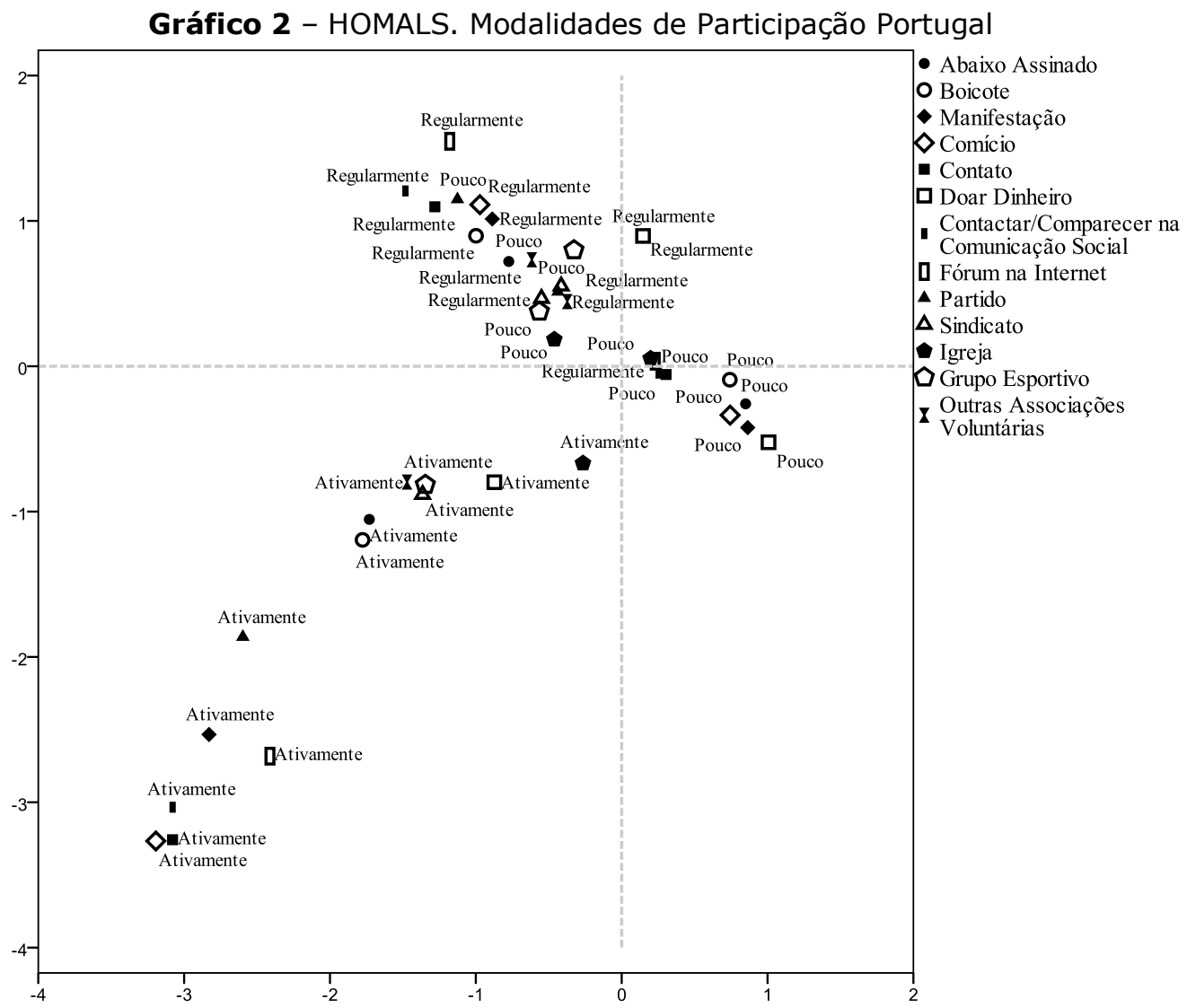

Fonte: Elaboração própria. 


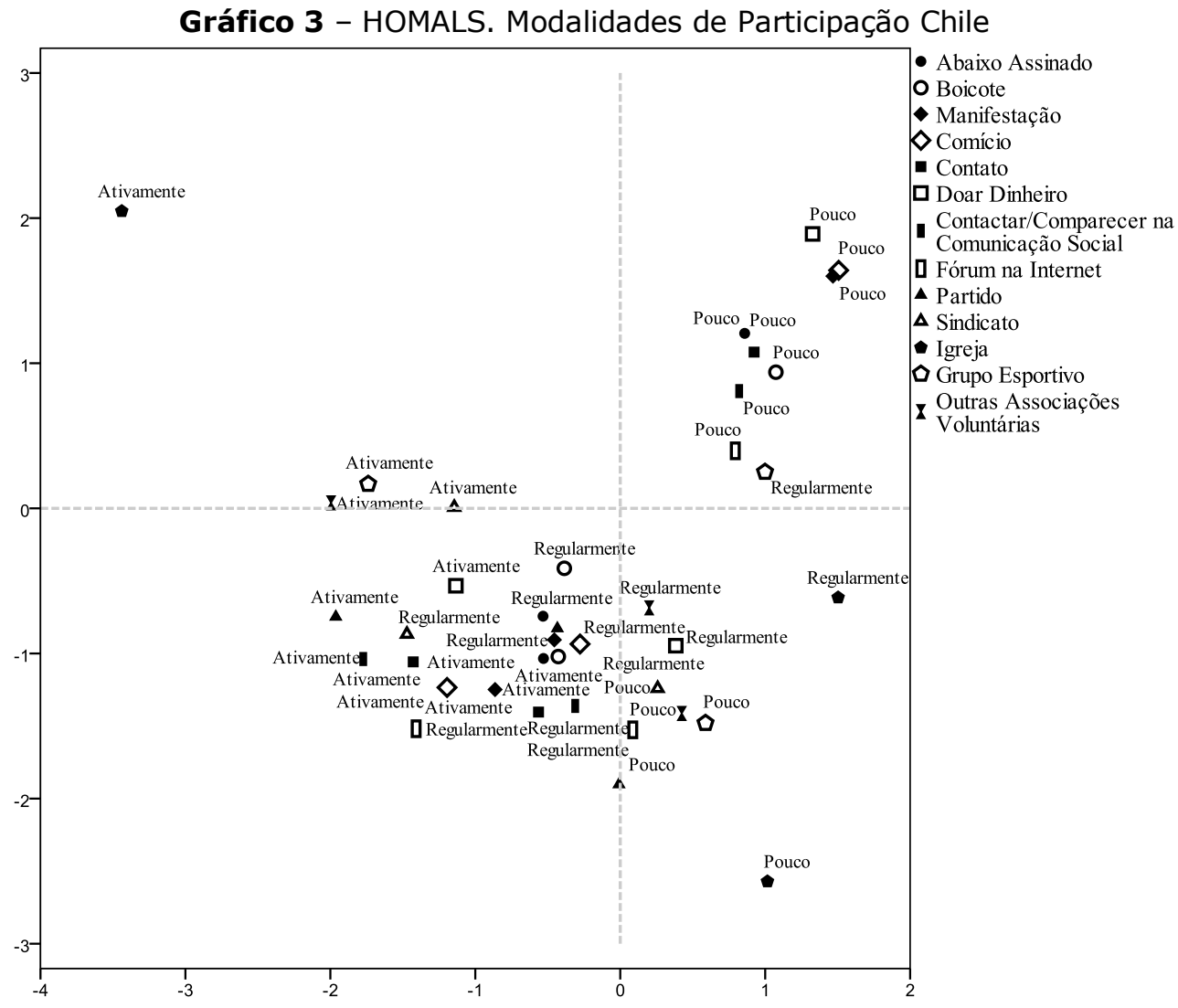

Fonte: Elaboração própria.

Os gráficos acima permitem verificar num plano bidimensional a articulação entre as modalidades individuais e a intensidade da participação. Nesse caso, o Brasil é o país onde fica mais visível o caráter homogêneo e convergente (das modalidades e da intensidade). Ou seja, os ativistas são ativistas nas treze modalidades do estudo. Já aqueles que participam de modo eventual ou não participam formam dois outros quadrantes, também claramente identificados, porém com alguma interface entre eles. No caso de Portugal, apesar da menor proximidade entre as variáveis, também verificase que aqueles que participam ativamente estão localizados num único quadrante, diferenciando-se dos demais. Menos claro é o caso do Chile, onde o agrupamento se deu entre as diversas modalidades de participação nas intensidades regular e ativa. De qualquer forma, elas ficam relativamente diferenciadas do quadrante dos que participam pouco. O caso do Chile confirma o que já haviamos encontrado na análise de regressão, onde os efeitos das variáveis de participação umas sobre as outras, foram os menores. 
Em alguns casos foi mesmo inexistente, como foi o da participação em partidos sobre outras associações políticas e o inverso, das associações políticas sobre os partidos.

\section{Considerações Finais}

Os resultados do presente trabalho confirmam as proposições teóricas que identificam as modalidades de participação como convergentes. Nesse sentido, o fato de um cidadão ser engajado em qualquer forma de participação (entre aquelas estudadas) é, em geral, um forte preditor de seu engajamento em qualquer outra modalidade. Apesar das diferenças internas entre os países em análise e do fato de que tais eviências tenham ficado mais claras para o Brasil e Portugal, a constatação acima tem validade para todo o universo da pesquisa.

Quais os significados e consequências empíricas e teóricas de tais constatações?

Em primeiro lugar parece que fica confirmado que o ativismo político é fruto de determinados atributos individuais (como a forma de socialização, os recursos individuais como renda e escolaridade e as redes da relações) que tornam possível a expressão de uma "identidade militante", que se materializa no exercício da participação política em diferentes modalidades.

Essas evidências questionam os enfoques que identificam uma "divisão de trabalho" entre os ativistas políticos, como por exemplo em Inglehart e Welzel (2009) ou Norris (2002), que diferenciam os perfis de ativistas em função de seus conjuntos de valores. Enquanto os "cidadãos críticos" ou "pós materialistas" direcionariam suas ações para modalidades não convencionais ou contestórias, os "materialistas" estariam vinculados às modalidades tradicionais ou eleitorais de participação. Apesar de nosso survey não nos possibilitar o teste empírico de tais teorias, parece evidente que no conjunto dos três países analisados existe uma forte articulação entre praticamente todas as modalidades de participação, em que pese 0 fato de que as associações mais fortes sejam identificadas internamente aos agrupamentos (ação política e participação associativa) e sejam mais fortes em Portugal e no Brasil que no Chile.

Temos também que relativizar o fato de que os três países em análise são fundamentalmente "materialistas" na linguagem de Inglehart, onde apenas uma pequena parcela de suas populações são portadoras dos valores do "pós materialismo". Dados de 1999 indicavam que no Brasil os pós materialistas eram 9\% da população. Em Portugal, 11,1\% e no Chile 16,9\%. Em dados de 2006 o Brasil aparece com o mesmo percentual contra 12,6\% do Chile. Para esse ano não temos dados de Portugal. De qualquer forma, o fato de Chile estar acima de Portugal e Brasil em termos de pós materialistas deve ser um elemento a se considerar no fato de que ali as relações entre as modalidades de participação tenham sido menos evidentes. 
Um segundo elemento a ser abordado é quanto às consequencias teóricas de nossos achados empíricos, em especial no que se refere ao debate sobre sociedade civil. A influência habermasiana nesse debate consolidou uma concepção de sociedade civil como um espaço social dotado de uma dinâmica própria, definida sobretudo pelo seu distanciamento entre as esferas do mercado e do Estado. Nesse sentido, os ativistas de tal sociedade civil atuariam numa esfera situada em torno dos novos movimentos sociais, cujas demandas se organizam em torno de questões ligadas aos temas da identidade, da cultura e do meio ambiente. A materialização organizacional da sociedade civil seriam as ONGs e outras modalidades do associativismo civil ligados a tais causas (as modalidades de "mobilização política" em nosso estudo, podem ser tomadas como uma proxy de participação organizações da sociedade civil). A expectativa teórica do modelo da sociedade civil é que tais organizações, por serem auto-limitadas, não se relacionariam com as esferas de participação organizadas em torno do mercado (p. ex. sindicalismo) e do Estado (p. ex. partidos políticos).

Ora, o que nossos dados indicam é que para os três países a lógica de ação dos ativistas é justamente o inverso do que está previsto por este modelo, ou seja, como já destacamos, ser ativista é participar em diferentes modalidades. A escolha por qual delas parece ser muito mais em função de oportunidades e constrangimentos oferecidos pelo contexto do que por um caráter auto-limitado de tais atores!

Como indicação para futuros estudos cabe verificar em que medida, incluindo-se outros contextos na análise, como por exemplo países com maiores níveis de modernização sócio-econômica, tais evidências empíricas continuam sendo verificáveis.

Julian Borba é Doutor em Ciência Política (UFRGS) e Mestre em Sociologia Política (UFSC), Professor do Departamento de Sociologia e Política da Universidade Federal de Santa Catarina.

E-mail: borbajulian@yahoo.com.br

\section{Referências}

ALMOND, Gabriel; VERBA, Sidney. The civic culture: political attitudes and democracy in five nations. Princeton: Princeton University Press, 1963.

AVELAR, Lúcia. Participação política. In: AVELAR, Lúcia; CINTRA, Antônio Octávio (orgs.). O. Sistema político brasileiro: uma introdução. Rio de Janeiro/São Paulo: Fundação Konrad Adenauer/Editora da UNESP, 2004. p. 261-280. 
AVRITZER, Leonardo. A moralidade da democracia. São Paulo: Perspectiva, 1996.

BAQUERO, Marcello; PRÁ, Jussara. Democracia brasileira e cultura política no Rio Grande do Sul. Porto Alegre: UFRGS, 2007.

BARNeS, Samuel H.; KAASE, Max. Political Action: mass participation in five western democracies. Beverly Hills: Sage Publications, 1979.

BOHRNSTEDT, George W.; KNOKE, David; MEE, Alisa. Statistics for Social Data Analysis. New York: Peacock, 1982.

BORBA, Julian. Modalidades de participação: uma revisão dos modelos de classificação. Lisboa, (mimeo), 2011.

BRADY, Henry E. Political participation. In: ROBINSON, John P.; SHAVER, Phillip R.; WRIGHTSMAN, Lawrence S. (Eds.). Measures of political attitudes. San Diego: Academic Press, 1999. p. 737-801.

CABRAL, Manuel V. Civic and political participation: a new culture shift? evidence from 12 countries. In: Congresso da Sociedade Brasileira de Sociologia. Rio de Janeiro, 14., 2009.

CATTERBERG, Gabriela. Evalutions, referents of support, and political action in new democracies. International Journal of Comparative Sociology, Irvine, v. 44, n. 3, p. 173-198, jun. 2003.

CLARK, Terry Nichols; HOFFMANN-MARTINOT, Vincent. The new political culture. Boulder: Westview Press, 1998.

COHEN, Jean; ARATO, Andrew. Civil society and political theory. Cambridge: The Mit Press, 1992.

COSTA, Sérgio. As cores de ercília. Belo Horizonte: UFMG, 2002.

DALTON, Russel J. Citizen politics: Public opinion and participation in advanced industrial democracies. 3. ed. New York: Seven Bridges Press, 2002.

DALTON, Russel J.; WATTENBERG, Martin P. Parties without partisans: political change in advanced industrialized democracies. Oxford: Oxford University Press, 2001. 
DELLA PORTA, Donatella. Introdução à Ciência Política. Lisboa: Editorial Estampa, 2003.

ERICKSON, Bonnie H.; NOSANCHUK, Terrance Aaron. How an apolitical association politicizes. Canadian Review of Sociology and Anthropology, Mississauga, v. 27, n. 2, p. 206-219, may 1990.

FIGUEIRA, Ana Paula. Procedimento HOMALS. Utilização na área de Ciências Sociais e Humanas. Exemplo ilustrativo. Disponível em: <http://www.psicologia.com.pt/artigos/imprimir.php?codigo=A0139>. Acesso em: 31 mar. 2011.

HAIR, Joseph et. al. Multivariate data analysis. New York: Macmillan Publishing, 1984.

HUNTINGTON, Samuel. A Terceira onda de democratização. São Paulo: Ática, 1994.

INGLEHART, Ronald; CATTERBERG, Gabriela. Trends in political action: the development trend the post-honeymoon decline. International Journal of Comparative Sociology, Irvine, v. 43, n. 3-5, p. 300-316, out. 2002.

INGLEHART, Ronald; WELZEL, Christian. Modernização, mudança cultural e democracia: a sequência do desenvolvimento humano. São Paulo: Francis, 2009.

ISSP. International Social Survey Programme. Citizenship (ISSP 2004). 2004. Disponível em: <http://zacat.gesis.org/webview/index.jsp?object=http// zacat.gesis.org/obj/fStudy/ZA3950>. Acesso em: 01 dez. 2010.

LAVALLE, Adrian Gurza. Sem pena nem gloria: o debate da sociedade civil nos anos 1990. Novos Estudos CEBRAP, São Paulo, s/v., n. 66, p. 91-110, jul. 2003.

LEIGHLEY, Jan. Group membership and the mobilization of political participation. The Journal of Politics, Austin, v. 58, n. 2, p. 447-463, may 1996.

MILBRATH, Lester. Political Participation: how and why do people get involved in politics? Chicago: Rand McNally, 1965.

NORRIS, Pippa. Critical Citizens: global support for democratic government. Oxford: Oxford University Press, 1999. 
- Democratic phoenix: reinventing political activism. Cambridge: Cambridge University Press, 2002.

. Political activism: new challenges, new opportunities. In: BOIX, Carles; STOKES, Susan (orgs.). The oxford handbook of comparative politics. Oxford: Oxford University Press, 2007. p. 628-652. Disponível em: <http://ksghome.harvard.edu/ pnorris/Acrobat/Boix\&stokes-chap26.pdf>. Acesso em: 02 fev. 2009.

PUTNAM, Robert. Comunidade e democracia: a experiência da Itália moderna. Rio de Janeiro: FGV, 1996.

2003.

(Org.). El declive del capital social. Barcelona: Galaxia Gutenberg,

STOLLE, Dietlind; HOOGHE, Marc. Emerging repertories of political action? A review of the debate on participation trends in Western Societies. In: ECPR Joint Sessions. Uppsala, Sweden, 2004. Disponível em: <http://www. kuleuven.be/facdep/social/pol/docs/0404-MH-ECPR.pdf>. Acesso em: $30 \mathrm{dez}$. 2004.

TEORELL, Jan; TORCAL, Mariano; MONTERO, Jose Ramon. Political participation: Mapping the terrain. In: VAN DETH, Jan; MONTERO, Jose R.; WESTHOLM, Anders (Eds.). Citizenship and involvement in european democracies: a comparative analysis. London: Routledge, 2007. p. 334-357.

TILLY, Charles. Regimes and repertories. Chicago: Chicago University Press, 2006.

VAN DETH, Jan. Studying political participation: towards a theory of everything? In: ECPR Joint Sessions. Grenoble, France, 2001.

VERBA, Sidney; NIE, Norman H. Participation in America. Political democracy and social equality. New York: Harper \& How, 1972.

VERBA, Sidney; SCHLOZMAN, Kay L.; BRADY, Henry. Voice and equality. Civic voluntarism in American politics. Harvard: Harvard University Press, 1995.

WELZEL, Christian; INGLEHART, Ronald; DEUTSCH, Franziska. Social capital, voluntary associations and collective action: which aspects of social capital have the greatest 'Civic' Payoff? Journal of Civil Society, Heidelberg, v. 1, n. 2, p. 121-146, 2005. 


\section{Anexos}

Tabela 1 - Associações Individuais entre modalidades de participação

\begin{tabular}{|c|c|c|c|c|c|c|c|c|c|c|c|c|}
\hline & $\begin{array}{c}\text { Ab. } \\
\text { Assinados }\end{array}$ & Boicote & $\begin{array}{l}\text { Manifes- } \\
\text { tações }\end{array}$ & Comício & Contato & Dinheiro & $\begin{array}{l}\text { Comp } \\
\text { Com. } \\
\text { Social }\end{array}$ & Fórum & Partidos & Sindicatos & Igreja & $\begin{array}{c}\text { Grupos } \\
\text { esportivos }\end{array}$ \\
\hline Ab. Assinados & 1 & & & & & & & & & & & \\
\hline Boicote &, 660 & 1 & & & & & & & & & & \\
\hline Manifestações &, 631 & ,578 & 1 & & & & & & & & & \\
\hline Comicio & ,569 &, 522 & 821 & 1 & & & & & & & & \\
\hline Contato & 647 & 613 & 631 & ,714 & 1 & & & & & & & \\
\hline Dinheiro & ,398 &, 439 &, 257 &, 271 &, 422 & 1 & & & & & & \\
\hline $\begin{array}{l}\text { Comp.com. } \\
\text { Social }\end{array}$ & 554 & 494 & 574 & ,569 & 772 & 285 & 1 & & & & & \\
\hline $\begin{array}{c}\text { Fórum da } \\
\text { Internet }\end{array}$ & ,588 & ,596 & ,588 & ,566 & 697 & 158 & ,744 & 1 & & & & \\
\hline Partidos & 468 & ,317 & 601 & 687 & 559 & 215 & 424 & ,369 & 1 & & & \\
\hline Sindicatos & 451 & 254 & 414 & 430 & 472 & ,329 & 287 & 170 & ,574 & 1 & & \\
\hline Igrejas & ,013(NS) & ,066(ns) & ,039(ns) & ,091* & ,050(ns) & 161 &,- 006 &,- 039 & 266 & 276 & 1 & \\
\hline $\begin{array}{l}\text { Grupos } \\
\text { Esportivo }\end{array}$ & ,503 & 320 & 433 & ,437 & 458 & ,239 & ,402 & 410 & ,574 & 485 & 223 & 1 \\
\hline $\begin{array}{l}\text { Outras } \\
\text { Associações }\end{array}$ & ,445 & 292 & 324 &, 347 & 429 & 341 & 381 & ,302 & 480 & ,514 & 340 & 673 \\
\hline
\end{tabular}

*Sig. entre 001 e 0,005. Os demais, significantes a 0,000. 
Tabela 2 - Associações Individuais entre modalidades de participação

\begin{tabular}{|c|c|c|c|c|c|c|c|c|c|c|c|c|}
\hline \multicolumn{13}{|c|}{ Brasil } \\
\hline & $\begin{array}{c}\text { Ab. } \\
\text { Assi- } \\
\text { nados }\end{array}$ & Boicote & $\begin{array}{c}\text { Manifes- } \\
\text { tações }\end{array}$ & Comício & Contato & Dinheiro & $\begin{array}{l}\text { Comp } \\
\text { Com. } \\
\text { social }\end{array}$ & Fórum & Partidos & Sindicatos & Igreja & $\begin{array}{c}\text { Grupos } \\
\text { esportivos }\end{array}$ \\
\hline Ab. Assinados & 1 & $x$ & $x$ & & & & & & & & & \\
\hline Boicote & ,391 & 1 & & & & & & & & & & \\
\hline Manifestações & 448 & 477 & 1 & & & & & & & & & \\
\hline Comicio & ,301 & 266 & ,472 & 1 & & & & & & & & \\
\hline Contato & 352 & ,501 & 492 & ,489 & 1 & & & & & & & \\
\hline Dinheiro & 308 & 368 & 385 &, 355 &, 549 & 1 & & & & & & \\
\hline $\begin{array}{l}\text { Comp.com. } \\
\text { Social }\end{array}$ & 393 & 507 &, 594 & 392 &, 725 &, 577 & 1 & & & & & \\
\hline $\begin{array}{l}\text { Fórum da } \\
\text { Internet }\end{array}$ & 421 & ,550 & ,605 & ,404 &, 652 &, 533 & 779 & 1 & & & & \\
\hline Partidos & 290 & 311 & 327 &, 502 & ,451 & ,291 & ,449 & ,334 & 1 & & & \\
\hline Sindicatos &, 344 & ,318 &, 344 & ,309 & ,321 & ,191 &, 384 &, 382 &, 520 & 1 & & \\
\hline Igrejas & 092* &, $051(\mathrm{~ns})$ &, 053 & 146 & 223 & 169 & 166 & 164 & 161 & ,207 & 1 & \\
\hline $\begin{array}{l}\text { Grupos } \\
\text { Esportivo }\end{array}$ & 381 & ,416 & ,398 & ,305 & ,411 & 212 & ,474 & ,567 & 317 & ,495 & 239 & 1 \\
\hline $\begin{array}{l}\text { Outras } \\
\text { Associações }\end{array}$ & ,364 & ,346 & 419 & 290 & ,395 & 281 & ,519 & 509 & 523 & ,435 & ,313 & ,664 \\
\hline
\end{tabular}

*Sig. entre 001 e 0,005. Os demais, significantes a 0,000. 
A SITUAÇÃO DAS AMÉRICAS: DEMOCRACIA, CAPITAL SOCIAL E EMPODERAMENTO

Tabela 3 - Associações Individuais entre modalidades de participação

\section{Chile}

\begin{tabular}{|c|c|c|c|c|c|c|c|c|c|c|c|c|}
\hline & $\begin{array}{c}\text { Ab. } \\
\text { Assi- } \\
\text { nados }\end{array}$ & Boicote & $\begin{array}{c}\text { Manifes- } \\
\text { tações }\end{array}$ & Comício & Contato & Dinheiro & $\begin{array}{l}\text { Comp } \\
\text { Com. } \\
\text { social }\end{array}$ & Fórum & Partidos & Sindicatos & Igreja & $\begin{array}{c}\text { Grupos } \\
\text { esportivos }\end{array}$ \\
\hline Ab. Assinados & 1 & & & & & & & & & & & \\
\hline Boicote & ,651 & 1 & & & & & & & & & & \\
\hline Manifestações &, 686 & ,731 & 1 & & & & & & & & & \\
\hline Comicio &, 632 & ,702 &, 890 & 1 & & & & & & & & \\
\hline Contato & ,617 &, 642 &, 664 &, 684 & 1 & & & & & & & \\
\hline Dinheiro &, 471 &, 555 &, 528 &, 519 &, 543 & 1 & & & & & & \\
\hline Com. Social &, 673 & ,755 & ,722 & ,718 & ,794 & ,589 & 1 & & & & & \\
\hline Internet & ,720 &, 812 &, 822 &, 806 & ,765 &, 574 &, 915 & 1 & & & & \\
\hline Partidos &, 531 &, 406 &, 619 &, 677 &, 616 & ,352 & ,590 &, 664 & 1 & & & \\
\hline Sindicatos & ,348 &, 412 &, 509 &, 507 & ,397 & ,286 & 362 &, 424 &, 626 & 1 & & \\
\hline Igrejas & ,129* &, $006(\mathrm{~ns})$ & ,014(ns) & ,038(ns) &, 161 & ,216 & ,138* & ,029(ns) & ,196* & ,175* & 1 & \\
\hline $\begin{array}{l}\text { Grupo } \\
\text { Esportivo }\end{array}$ & ,322 &, 312 &, 374 &, 331 & ,356 & ,348 & 407 &, 442 & ,483 & ,403 & 266 & 1 \\
\hline $\begin{array}{l}\text { Outras } \\
\text { Associações }\end{array}$ & ,362 & ,363 & 422 & ,395 & 370 & 462 & 452 & ,462 & ,496 &, 364 & 235 & 605 \\
\hline
\end{tabular}

*Sig. entre 001 e 0,005. Os demais, significantes a 0,00

Texto recebido em 29/02/2012.

Aprovado em 04/04/2012. 